\title{
ANTIHISTAMINASE ACTIVITY OF SERPENTINE
}

\author{
BY \\ K. S. SACHDEV, RANITA AIMAN,* AND M. V. RAJAPURKAR \\ From the Department of Pharmacology, M. P. Shah Medical College, Jamnagar
}

(Received November 22, 1960)

\begin{abstract}
Serpentine, an alkaloid of Rauwolfia serpentina, specifically potentiates histamine responses of guinea-pig ileum, uterus, and tracheal chain. It also inhibits histaminase in vitro. Its antihistaminase activity is equivalent to that of aminoguanidine.
\end{abstract}

Chatterjee \& Hausler (1955) have reported antiacetylcholine and antihistamine actions of a total alkaloidal preparation of Rauwolfia serpentina on the guinea-pig ileum.

During a study of the pharmacology of serpentine, one of the alkaloids of Rauwolfia serpentina, by one of the authors (Sachdev, 1958), it was noted that serpentine markedly and consistently potentiated the response of the guinea-pig ileum to histamine. Arunlakshana, Mongar, and Schild (1954) demonstrated that potentiation of the histamine response of guinea-pig ileum, uterus, and tracheal chain by semicarbazide, hydroxylamine, guanidine, and aminoguanidine could be attributed to inhibition of diamine oxidase or histaminase. Murexine and dihydromurexine (Tabachnick \& Roth, 1957) and stilbamidine (Lindell \& Westling, 1954) have also been reported to show similar potentiation of histamine responses and inhibition of histaminase. Sachdev \& Aiman (1957), in a preliminary report, showed that serpentine potentiated the action of histamine on the guinea-pig ileum and inhibited histaminase. In this paper we have demonstrated a potentiation of histamine response of organs shown by Arunlakshana, Mongar \& Schild (1954) to be rich in histaminase and inhibition of histaminase in vitro by serpentine, and have compared its antihistaminase activity with that of aminoguanidine.

\section{METHODS}

Guinea-pig ileum. The terminal part of the guinea-pig ileum was obtained after killing the animal with a blow on its head. About an inch of this was cleaned and suspended in a 10-ml. isolated organ bath containing oxygenated Tyrode solution at 36 to $37^{\circ} \mathrm{C}$. Repeated responses to histamine (histamine acid phosphate, British Drug Houses) were elicited every 2 min, until the preparation became stabilized; the drug was allowed to act for $30 \mathrm{sec}$. A few graded responses of histamine were elicited. A suitable dose was chosen and repeated 4 to 5 times. This dose of histamine (expressed as the base) was usually between 0.01 and $0.03 \mu \mathrm{g} / \mathrm{ml}$. Thirty sec before each dose one of the potentiating drugs (serpentine and aminoguanidine) was added to produce one of the following concentrations in the bath: $10^{-9}, 10^{-8}, 10^{-7}$, $10^{-6}$, and $10^{-5} \mathrm{~g} / \mathrm{ml}$. The potentiating drug was added until maximum potentiation was obtained. Thereafter it was omitted and repeated responses of histamine elicited until these

*Present address: Department of Pharmacology, B.J. Medical College, Poona. 
returned to control levels. The potentiation was measured in terms of an equivalent dose of histamine. The procedure of Arunlakshana, Mongar \& Schild (1954) was followed. In some experiments atropinized ileum was used.

Guinea-pig uterus. This preparation was suspended in the same way as ileum. The responses to histamine were elicited every $5 \mathrm{~min}$. Histamine was allowed to act for $1 \mathrm{~min}$ and then washed out. The potentiating drug was added in the same concentration as used for the ileum but for $1 \mathrm{~min}$ before the response of histamine was elicited.

Guinea-pig tracheal chain. The method described by Castillo \& de Beer (1947) was followed. The rings of the trachea were, however, cut in the middle of the cartilage and tied end to end.

The histamine responses were registered for $10 \mathrm{~min}$. After eliciting responses to a few graded doses of histamine usually between $10^{-7}$ and $5 \times 10^{-6} \mathrm{~g} / \mathrm{ml}$, , one of the previously mentioned concentrations of the potentiating drug was added $4 \mathrm{~min}$ before the next histamine response. Histamine was added to the bath without removing the potentiating drug.

Histaminase in vitro. $5 \mathrm{mg} / \mathrm{ml}$. of histaminase (Torantil, Hoechst) solution in phosphate buffer at $p \mathrm{H} 7.2$ was incubated for $30 \mathrm{~min}$ at $37^{\circ} \mathrm{C}$ in an atmosphere of oxygen in a metabolic shaker, with $10^{-6} \mathrm{~g} / \mathrm{ml}$. of histamine as substrate, with and without various concentrations of serpentine $\left(10^{-8}, 10^{-7}, 10^{-6}, 10^{-5}\right.$, and $10^{-3} \mathrm{~g} / \mathrm{ml}$.). After incubation the histaminase was destroyed by boiling. These solutions were assayed for histamine on atropinized guinea-pig ileum. At least three assays were done for each solution. As histaminase is inactive in the absence of oxygen, one incubation was carried out anaerobically as a control. The final solution after heat inactivation of the histaminase was assayed for histamine. Serpentine was used as the hydrochloride. The doses mentioned in the text represent the quantity of the base.

\section{RESULTS}

Guinea-pig ileum. Serpentine in a concentration of $10^{-9} \mathrm{~g} / \mathrm{ml}$. produced minimal potentiation. Maximum potentiation (doubling the responses to histamine) was seen with $10^{-8}$ and $10^{-7} \mathrm{~g} / \mathrm{ml}$. of serpentine (Fig. 1). Higher concentrations than

$a$

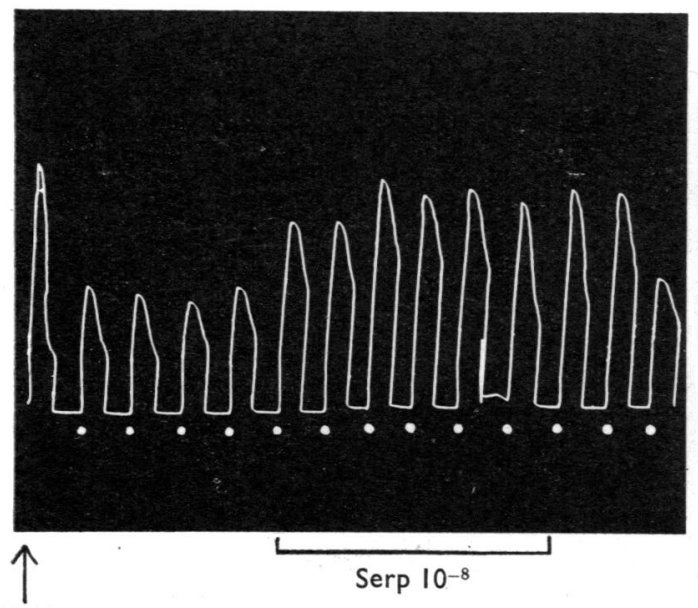

b

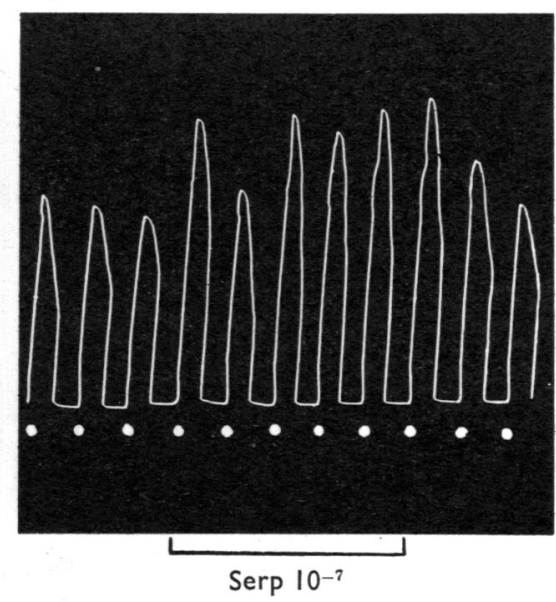

$\mathrm{H} \times 2$

Fig. 1. Responses of guinea-pig ileum to $0.02 \mu \mathrm{g} / \mathrm{ml}$. of histamine, added at white dots, and washed after $30 \mathrm{sec}$, except $\mathrm{H} \times 2$, which is the response to $0.04 \mu \mathrm{g} / \mathrm{ml}$. Serpentine $\left(10^{-8}\right.$ and $\left.10^{-7}\right)$ was added $30 \mathrm{sec}$ before each histamine response between the bracket. Note potentiation of the histamine response. 


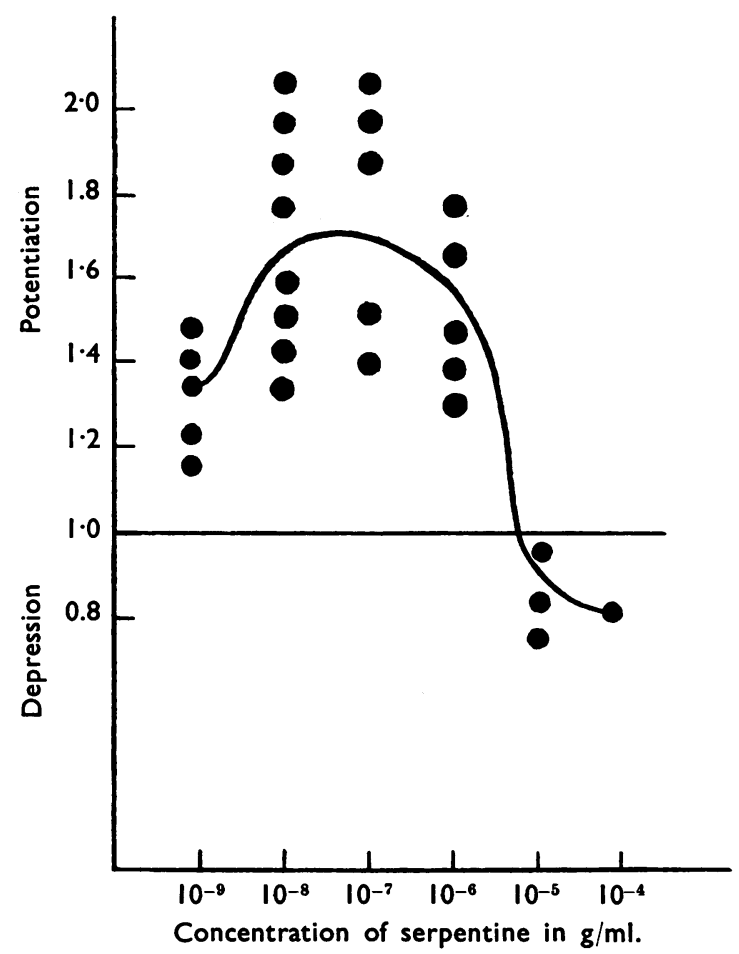

Fig. 2. Potentiation and depression of histamine response of guinea-pig ileum plotted against concentrations of serpentine. Measurement of each potentiation or depression in each experiment, represented by a dot, was made in terms of an equivalent dose of histamine.

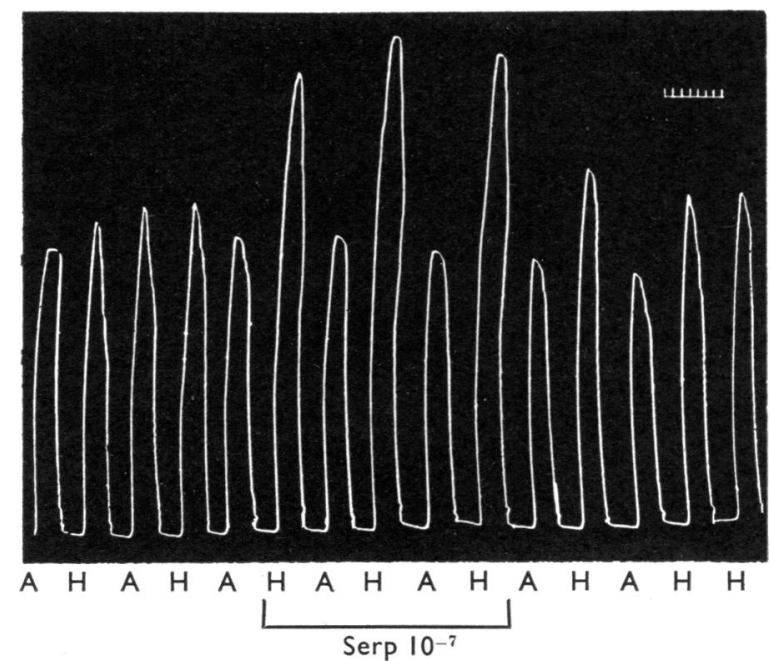

Fig. 3. Responses of guinea-pig ileum to acetylcholine (A) $0.2 \mu \mathrm{g} / \mathrm{ml}$., histamine (H) $0.02 \mu \mathrm{g} / \mathrm{ml}$. Serpentine $10^{-7}$ potentiated only histamine responses. 
$10^{-6}$ of serpentine raised the base line tone and depressed the histamine response. Fresh pieces of guinea-pig ileum showed better potentiation than ones kept in the refrigerator. The potentiation and depression of the histamine response on guineapig ileum by various concentrations are shown in Fig. 2.

Atropinization of ileum did not affect the potentiation. Alternating equipotent responses of acetylcholine and histamine were differentially affected by serpentine ; while histamine responses were potentiated, the acetylcholine responses were not affected or sometimes depressed (Fig. 3).

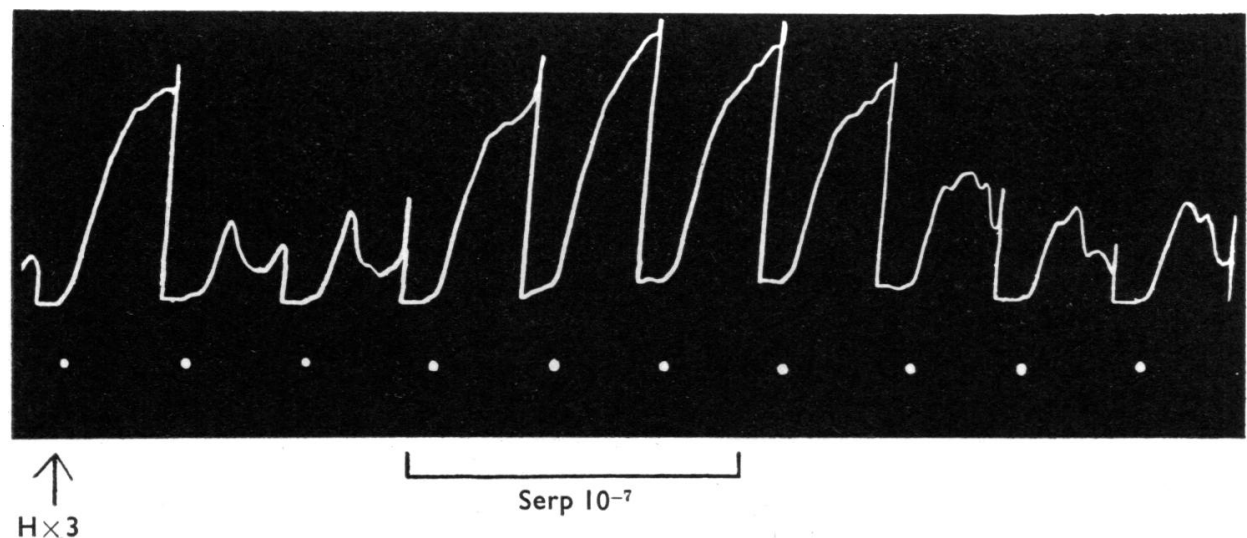

Fig. 4: Isolated guinea-pig uterus. At all white dots a response to $0.2 \mu \mathrm{g} / \mathrm{ml}$. histamine, except $\mathrm{H} \times 3$, where $0.6 \mu \mathrm{g} / \mathrm{ml}$. histamine was given. $10^{-7}$ serpentine added $1 \mathrm{~min}$ before histamine response potentiated the response by more than three times.

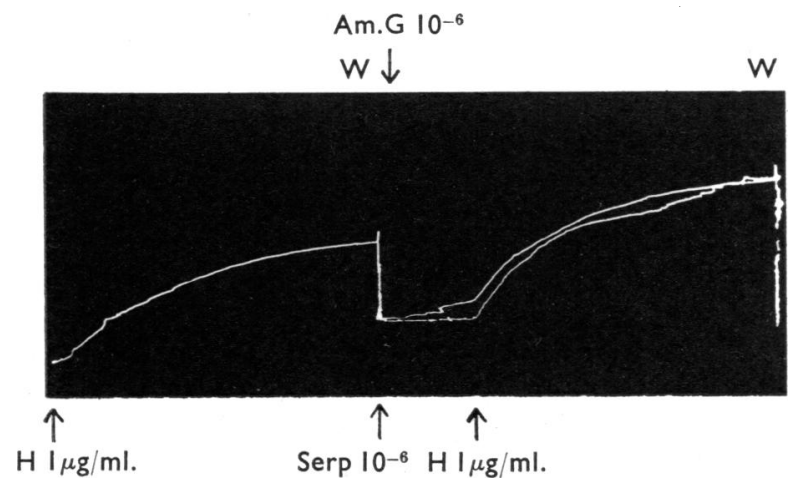

Fig. 5. Tracheal chain of guinea-pig. Three responses to $1 \mu \mathrm{g} / \mathrm{ml}$. histamine (H). The first is a control. The latter two responses are superimposed. For $4 \mathrm{~min}$ before the lower response, the tissue was exposed to $10^{-\infty} \mathrm{g} / \mathrm{ml}$. of serpentine (Serp). After eliciting the potentiated response of histamine and repeated washing until histamine responses returned to control level, the drum was moved back at 4 min before the upper superimposed response to histamine, aminoguanidine (Am.G) was added, to get a concentration of $10^{-6}$ in the bath. Note that serpentine and aminoguanidine produce equivalent potentiations. 
Guinea-pig uterus. As indicated by Arunlakshana, Mongar \& Schild (1954), only a few preparations could be stabilized. Minimal potentiation of histamine responses was obtained with $10^{-8}$ of serpentine. Maximal potentiation (three- or four-fold) occurred with concentrations of serpentine between $10^{-7}$ and $10^{-6}$ (Fig. 4). Higher concentrations produced marked rhythmic activity of the uterus.

Guinea-pig tracheal chain. Minimal potentiation of the histamine response was obtained with $10^{-8}$ of serpentine. $10^{-7}$ and $10^{-6}$ of serpentine produced the maximal potentiation (Fig. 5). Maximum potentiation obtained was 4 times the histamine response. Higher concentrations raised the base line and depressed the histamine response.

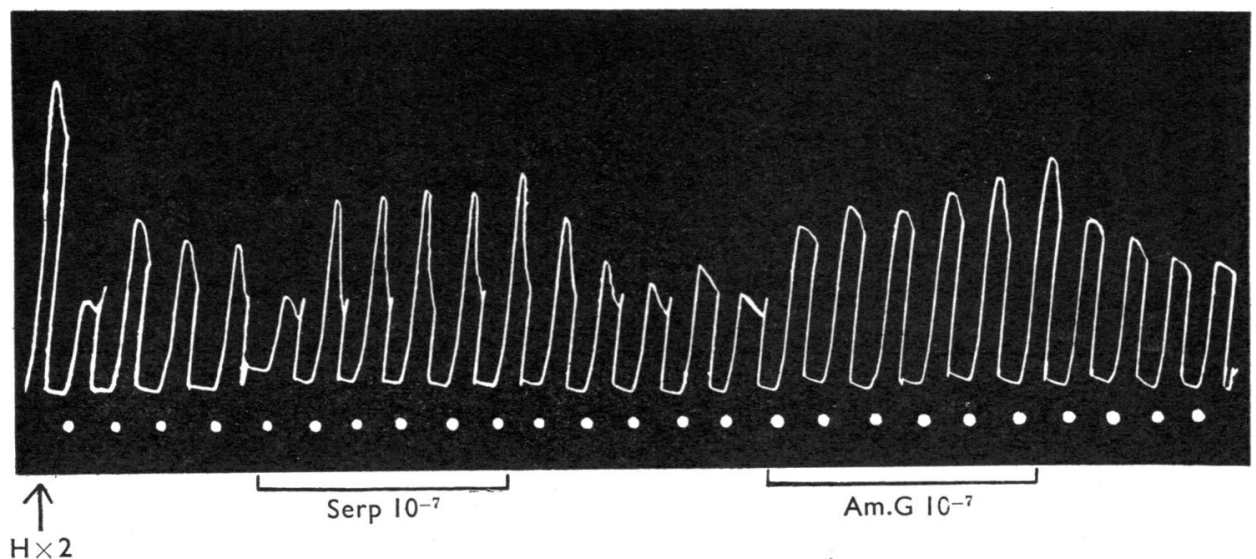

Fig. 6. Responses of guinэa-pig ileum to $0.02 \mu \mathrm{g} / \mathrm{ml}$. histamine given at white dots. $\mathrm{H} \times 2$ is a response to $0.04 \mu \mathrm{g} / \mathrm{ml}$. histamine. Serpentine (Serp 10-7) and aminoguanidine (Am.G 10-7) added at the bars. Note that there is a similar potentiation of histamine response after serpentine and aminoguanidine.

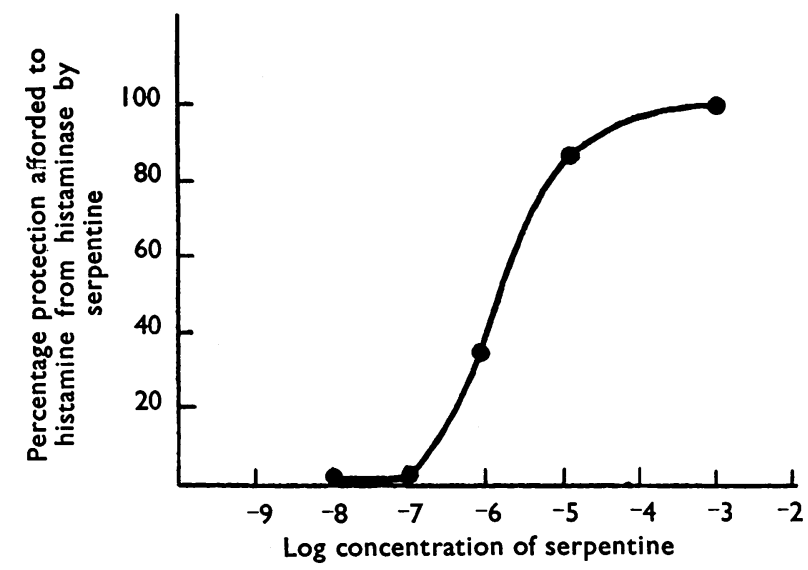

Fig. 7. The inhibition of histaminase by serpentine in vitro. 
Comparison of serpentine and aminoguanidine. The potentiating activity of serpentine was compared with that of aminoguanidine on guinea-pig ileum and tracheal chain. Each comparative study was performed on the same strip of tissue. It was seen that the potentiation produced by equal concentrations of aminoguanidine and serpentine was approximately the same, on both guinea-pig ileum and tracheal chain. For comparisons only the concentrations producing the maximal potentiation were used (that is, $10^{-7}$ and $10^{-6}$ ) (Figs. 5 and 6).

In vitro experiments. Aerobic incubation of histaminase with histamine $\left(10^{-6}\right)$ at $37^{\circ} \mathrm{C}$ with and without various concentrations of serpentine showed that the minimal concentration of serpentine showing inhibition of histaminase activity was $10^{-6}$. With higher concentrations of serpentine the inhibition of histaminase rose steeply. The protection afforded to histamine by serpentine when plotted against the concentration of serpentine showed an S-shaped curve (Fig. 7). Anaerobic incubation of histaminase with histamine produced no destruction of histamine.

\section{DISCUSSION}

We have demonstrated that serpentine potentiates histamine responses of guineapig ileum, uterus, and tracheal chain, organs shown by Arunlakshana, Mongar \& Schild (1954) to be rich in histaminase. This potentiation is specific, as acetylcholine responses are not affected by serpentine. The potentiating activity of serpentine is of the same order of magnitude as that of aminoguanidine, which is a potent antihistaminase drug. Serpentine also inhibits the histamine-inactivating action of histaminase (Torantil), in vitro.

Antihistaminase activity has been described in various types of compounds. Many are carbonyl reagents (Arunlakshana, Mongar \& Schild, 1954). The indole grouping has been implied to possess antihistaminase activity by Tabachnick \& Roth (1957). Although it is present in both serpentine and reserpine, the latter does not show any antihistaminase activity. Reserpine neither potentiates the histamine response of guinea-pig ileum nor inhibits histaminase in vitro (unpublished observations). In fact it depresses the histamine responses of guinea-pig ileum.

Therapy with Rauwolfia serpentina is known to cause some histamine-like side effects such as nasal congestion, increased gastric acidity, and bronchoconstriction. An interesting hypothesis to explain the increased gastric acidity produced by antihistaminases in spite of the absence of histaminase in gastric mucosa has been put forward by Irvine, Duthie, Ritchie \& Waton (1959). But since reserpine, which has no antihistaminase activity, produces increased gastric secretion, nasal stuffiness and bronchoconstriction, it is not reasonable to attribute the side effects of Rauwolfia therapy to the antihistaminase activity of serpentine. However, in serpentine we have a very potent antihistaminase drug which may be of use in experimental work.

We are thankful to Dr. B. P. Ghosh, of Gluconate Co., Calcutta, and Shri S. P. Bapat, of Hoechst Pharma., Bombay, for the liberal supplies of crystalline serpentine and Torantil respectively.

We thank Dr. S. S. Baxi, M.S., Dean, M. P. Shah Medical College, Jamnagar, for having scrutinized the text and permitted us to send the article for publication. 


\section{REFERENCES}

Arunlakshana, O., Mongar, J. L. \& Schild, H. O. (1954). Potentiation of pharmacological effects of histamine by histaminase inhibitors. J. Physiol. (Lond.), 123, 32-54.

CAstillo, J. C. \& DE BEeR, E. J. (1947). The tracheal chain. I. A preparation for the study of antispasmodics with particular reference to bronchodilator drugs. J. Pharmacol. exp. Ther., 90, $104-109$.

Chatterjee, M. L. \& Hausler, H. F. (1955). Anti-acetylcholine and anti-histamine actions of the total alkaloids of Rauwolfia serpentina Benth. Nature (Lond.), 176, 701.

Irvine, W. T., Duthie, H. L., Ritchie, H. D. \& Waton, N. G. (1959). The liver's role in histamine absorption from the alimentary tract. Its possible importance in cirrhosis. Lancet, 1, 1064 1068.

Lindell, S. E. \& Westling, H. (1954). Potentiation of histamine effects by an antihistaminase. Acta physiol. scand., 32, 230-237.

SACHDEv, K. S. (1958). Some aspects of the pharmacology of serpentine with special reference to its antihistaminase activity. Dissertation accepted by Poona University, India, as part of M.D. pharmacology examination.

Sachdev, K. S. \& Aiman, Ranita (1957). Potentiation of histamine response of guinea-pig ileum by serpentine. Curr. Sci., 26, 356-357.

TABACHNICK, I. I. A. \& RoTH, F. E. (1957). The potentiation of histamine by imidazoleacrylcholine (murexine) and imidazolepropionylcholine (dihydromurexine). J. Pharmacol. exp. Ther., 121, 191-198. 